by Neville Hodgkinson, the science correspondent of the Sunday Times and the author of the article, are familiar ones, and little attempt is made to provide detailed answers to the responses to claims made in earlier articles in the newspaper.

Much is made of the fact, for example, that new estimates of the global pattern of AIDS spread are not as high as some of the earlier estimates. But, as Professor Roy Anderson pointed out earlier this year ( $\mathrm{Na}$ ture 363, 393-394; 1993), the new figures are within the bounds of the original estimates, which were themselves known at the time to be subject to considerable uncertainty because of the lack of data which have since been collected.

Similarly, Hodgkinson repeats the claim that HIV-positive haemophiliacs have recovered after being treated for a bloodclotting disorder. But this claim is dismissed by the head of a haemophilia centre at one of London's main teaching hospitals, who says that she has explained to Hodgkinson why the view is wrong, and that repeating it is deeply distressing to affected people who may be given false hope.

(The comments on the "HIV theory" with respect to haemophiliacs is particularly odd given that, in a different part of the same edition of the Sunday Times, the paper congratulates itself for helping to win compensation for a group of British haemophiliacs who had been infected with HIV from contaminated US blood.)

Despite the aggressive style of the twopage attack on Nature and the (unnamed) supporters of what the newspaper describes as the "HIV theory", Hodgkinson appears to be backing off from the newspaper's position only the week before, when it promoted the views of a small but vociferous group of self-styled "dissidents" who do not believe that HIV causes AIDS.

In this week's article, Hodgkinson says "we have never argued that any of these findings rule out a role for HIV in Aids". His main complaint now is that Nature has not, he claims, examined the significance of the so-called anti-HIV results.

Such statements appear to ignore the many occasions on which Nature has indeed assessed some of the less generally accepted views on AIDS, most recently, for example, by M. Ascher et al. in Nature 364, 291-292; 1993.

Once again, the Sunday Times repeats the views of a few people who do not work with AIDS patients and say it is a disgrace that Nature has rejected their speculative hypotheses. In neither of its articles in the past two weeks has it reported the views of clinical researchers working with AIDS patients; nor has it reported the view of basic scientists who have published papers containing relevant data.

The newspaper appears to dismiss the views of such individuals on the grounds that they are part of what it describes as the "HIV industry".

Maxine Clarke

\title{
Fusion experiments give lift to future funding prospects
}

Washington. Physicists at the University of Princeton are this week starting to analyse data from a series of record-breaking experiments which they hope will help to establish the commercial potential of nuclear fusion.

The experiments were carried out at the Princeton University Plasma Physics Laboratory, which last week sustained a power output from fusion of as much as $6 \mathrm{MW}$ for three-quarters of a second. They were described by O'Leary, the Secretary of Energy, as "the most significant achievement in fusion energy in the past two decades."

Previously, the record for fusion power output was 1.7 MW, set at the Joint European Torus (JET) facility at Culham in Britain in 1991. But where the JET experiments used a plasma of 90 per cent deuterium and 10 per cent tritium, Princeton used a much more powerful 50:50 mixture of the two hydrogen isotopes, similar to that likely to be needed in commercial fusion reactors.

Ron Davidson, director of the Princeton laboratory, says that the duration of the fusion event is restricted by the ability of his equipment to store and deliver the $25 \mathrm{MW}$ of electricity needed to power the copper magnets. These suspend the plasma in space as it is heated to temperatures of more than 100 million degrees Kelvin.

The $1 \mathrm{GW}$ International Thermonuclear
Experimental Reactor(ITER), being planned for an unspecified site by the United States, Japan, Europe and Russia as the next fusion prototype, will use superconducting magnets which require far less power. As a result, it is hoped that ITER will be able to sustain a continuous and energy-efficient fusion reaction.

A programme of around a thousand fusion "shots" at Princeton will continue through this winter, providing vital data on the control of the plasma, on ways of removing heat from it, and on the best choice of reactor materials. The experiment will also study the effects of alpha radiation from fusion on the behaviour of the plasma itself.

The Department of Energy, which provides the Princeton facility's $\$ 80$ million budget, hopes that publicity from the experiments will help secure fusion funding in Congress, where sceptics complain that a fuel source which will yield no commercial energy until at least 2040 gets more research support than any other.

Congressional aides said that the fusion budget is unlikely to come under any real pressure next year. But laws have already been passed which make future United States support conditional on the ITER partners agreeing on an international framework for fusion research.

Colin Macilwain

\section{NSF opens network to Russian scientists}

Washington. Another barrier left over from the Cold War fell last week when NSFNET, the scientific information network of the US National Science Foundation, began carrying data from the former Soviet Union (FSU) for the first time.

The decision to allow such traffic was taken by the National Science Board, and will considerably ease electronic mail and data exchanges between FSU scientists and their US counterparts.

From its inception in 1986, NSFNET, which connects approximately 10 million users in federally sponsored research laboratories, colleges and universities, and forms one of the main backbones of the global network Internet, has had a policy of refusing traffic from FSU states.

As a result, although Soviet messages could find alternative routes through Internet, Steven Goldstein of the NSF's networking and communications research division estimates that at least 30 per cent of US sites were not directly accessible to FSU scientists. These scientists should now should be able to reach all those sites by electronic mail directly.

At the same time, the National Aero- nautics and Space Administration (NASA) has unveiled plans to link a group of Russian space scientists directly to its own NASA Science Internet - another major backbone of Internet - by early January. A satellite link will connect the Ames Research Center near San Francisco to Russia's Space Research Institute (IKI), which will act as the hub of a Russian network linking nine additional space research facilities.

The system will support collaborative projects in areas ranging from astrophysics to space life sciences. But its use will be restricted to scientists working on those projects. The US Department of Energy (DOE) plans a similar connection between its Energy Sciences Network and several Russian sites later in 1994.

Both the NASA and DOE efforts should benefit from work being completed in Moscow on wiring the city's leading research centres with fibre optic cable for high-quality communications. Funded by philanthropist George Soros's International Science Foundation (ISF), the work is expected to be completed next spring. Tony Reichhardt 